\title{
Quality of Life in Iranian Men With Spinal Cord Injury in Comparison With General Population
}

\author{
Manijeh Yazdanshenas Ghazwin ${ }^{1}$; Samira Chaibakhsh ${ }^{2}$; Sahar Latifi ${ }^{1}$; Amir Hossein \\ Tavakoli ${ }^{1,3,} ;$ Davood Koushki ${ }^{4}$ \\ ${ }_{1}^{1}$ Brain and Spinal Injury Research Center, Tehran University of Medical Sciences, Tehran, IR Iran \\ ${ }^{2}$ Department of Biostatistics, Shahid Beheshti University of Medical Sciences, Tehran, IR Iran \\ ${ }_{4}^{3}$ Iranian Tissue Bank Research Center, Imam Khomeini Complex Hospital, Tehran University of Medical Sciences, Tehran, IR Iran \\ ${ }^{4}$ Iran University of Medical Sciences, Tehran, IR Iran \\ *Corresponding author: Amir Hossein Tavakoli, Iranian Tissue Bank Research Center, Imam Khomeini Complex Hospital, Tehran University of Medical Sciences, Keshavarz BLV, Teh- \\ ran, IR Iran. Tel: +98-2166581561, Fax:+98-2166938885, E-mail: amirtavakoli1@yahoo.com
}

Received: July 2, 2014; Revised: September 6, 2014; Accepted: September 10, 2014

Background: Spinal cord injury (SCI) imposes a tremendous burden on physical, mental and psychosocial aspects of life among affected individuals.

Objectives: Until now, there was no statistics about the quality of life (QoL) in Iranian males with SCI. Here, we assessed the QoL among Iranian men with SCI and compared it with general population.

Patients and Methods: Referred male patients with SCI to Brain and Spinal Injury Research Center (BASIR) were invited to participate in this investigation. The QoL was measured by the Short-Form 36-Item Health Survey (SF-36). One sample T-test was used to compare outcomes with normal distribution. Values in general population in Iran were extracted from previous literatures.

Results: Total of 153 patients with mean age of $35.10 \pm 16.20$ years old participated in this study. The most common reason of trauma was road accidents (49.7\%). Cervical level injury was seen in $47 \%$ of patients, thoracic level in $28.1 \%$ and lumbosacral level in $24.9 \%$. QoL was assessed in eight domains. Mean scores in domain of physical functioning was significantly higher in general population (28.2 \pm 25.3 and $87.8 \pm 19.0$ in SCI group and general population, respectively, $\mathrm{P}<0.0001)$. Similarly, scores in domain of physical and emotional role functioning were higher in general population $(\mathrm{P}<0.0001$ and $\mathrm{P}=0.002$, respectively). No significant difference was seen between males with SCI and general population in domain of mental health (70.5 \pm 19.6 and $69.2 \pm 17.1$ in SCI group and general population, respectively; $\mathrm{P}=0.37$ ).

Conclusions:This study shows that men with SCI have significant reduced QoL in comparison with general population. However, it seems that the scores in domain of mental health are not affected by SCI and this aspect of QoL is spared to some extents after injury.

Keywords:Spinal Cord Injury; Quality of Life; Male; Iran

\section{Background}

Spinal cord injury (SCI) is a catastrophic event $(1,2)$ with an incident range of 10.4 to 83 per million each year. Its prevalence is estimated to be between 223 and 755 cases per million (3). SCI is accompanied with many complications including bowel dysfunction, impaired bladder control, mobility limitations, sexual dysfunction and increased risk of pressure ulcers, which leads to considerable changes in quality of life (QoL) (4). Although it is assumed that patients with SCI have poorer QoL (5), no statistics on the measures of QoL among Iranian men with disability has been reported up to now.

Attention to QoL is essential since it affects patients' ability to cope with their new situations (2). QoL is generally considered to be a multidimensional construct, primarily based on a person's subjective appraisal of their physical, functional, emotional, and social well-being (4). QoL is a multidimensional concept, which is usu- ally expressed subjectively by patients and assessed by self-report (5). Evidences support the fact that chronic illnesses affect health-related QoL (6), which is not only dependent on patients' physical conditions, but other factors including social and financial supports, culture and living conditions. Since QoL is affected by social and environmental factors, it is expected to observe differences on the scores of QoL among different nations. In this regard, it is essential that each nation provides its own their specific statistics on the level of QoL to understand the background condition in each subset of population. Among individuals with SCI, no definite statistics on the QoL in Iranian men could be found. However, some previous literatures have illustrated that scores of QoL among patients with disability is only slightly lower than in the general population $(7,8)$. Reduced QoL can be associated with subsequent complications such as depression, anxi-

Copyright (C) 2015, Tehran University of Medical Sciences. This is an open-access article distributed under the terms of the Creative Commons Attribution-NonCommercial 4.0 International License (http://creativecommons.org/licenses/by-nc/4.0/) which permits copy and redistribute the material just in noncommercial usages, provided the original work is properly cited. 
ety and drug abuse (9-15); thus, it is essential to evaluate the QoL among patients with SCI to describe the present condition of the affected individuals. These statistics can be cited in further investigations, which intend to examine QoL.

\section{Objectives}

The purpose of this study was to evaluate QoL in Iranian men with SCI and to compare their scores with those of the general population.

\section{Patients and Methods}

\subsection{Study Design and Participants}

In this cross-sectional study on patients referred to Brain and Spinal Injury Research Center (BASIR), data were collected by direct face to face interviews from April 2012 to January 2013. Participation in the study was voluntary. The study protocol was approved by ethical committee of Tehran University of Medical Sciences. Inclusion criteria were as follow: male gender, traumatic SCI, age range of 18-65 years and ability to speak and understand Persian language fluently. Exclusion criteria were as follow: existence of cognitive impairment, history of mental diseases, coincidental chronic diseases including diabetes, cancer, cardiovascular disorders, liver dysfunction, AIDS, kidney failure etc. and consumption of special medications such as antidepressants, steroids, hormones, anticonvulsive drugs, heparin, lithium and antipsychotics. Those patients with addiction to illegal drugs or with history of alcoholism were excluded as well.

\subsection{Measures}

Baseline characteristics including age, level of education, cause of injury, marital status and employment were asked during interviews and were indexed in preprepared forms. QoL was measured by Iranian version of Short-Form 36-Item Health Survey (SF-36). This questionnaire has been shown to have acceptable reliability and validity in Iranian population (16). The SF-36 questionnaire was scored by summing and transforming raw data for each of the eight domains as per the formula in the SF-36 manual. Higher scores on the 8 domains suggest higher Health Related-QoL. The eight SF-36 domains include: (1) physical functioning, indicating the extent to which a person's health limits their day to day physical activities; (2) role limitations at work or in the home due to physical health problems (role-physical); (3) bodily pain, indicating the extent to which pain interferes with daily activities; (4) general health status and perception of health; (5) vitality, a measure of a person's energy levels; (6) social function, indicating the extent to which health limits social activities; (7) role limitations due to emotional problems (role-emotional), indicating the extent to which a person's emotional problems impact on daily and work activities; and (8) mental health, indicating the amount of time a person experiences feelings of nervousness, depression, happiness, etc. (17).

Data on general population was extracted from Montazeri et al. study in Iranian population (16). The mean score and standard deviation (SD) of each of these eight domains were extracted and were entered into analysis for comparison with SCI population. In Montazeri et al. study, total number of participants was 4163 in which 1997 subjects were male. For proper comparison, only the data on male population entered into analysis in our investigation.

\subsection{Statistical Analysis}

All statistical analysis was performed using STATA software version 12 (STATA/C, StataCorp). Continuous variables are expressed by mean \pm SD and categorical data are presented by frequency number and percentages. One sample T-test was used for proper comparison of means with normal distribution. $\mathrm{P}<0.05$ was considered significant.

Table 1. Baseline Characteristics in Individuals With Spinal Cord Injury ${ }^{\mathrm{a}}$

\begin{tabular}{|c|c|}
\hline & SCI Males $(\mathrm{N}=153)$ \\
\hline Age & $35.10 \pm 16.20$ \\
\hline \multicolumn{2}{|l|}{ Marital Status } \\
\hline Single & $65(42.5)$ \\
\hline Married & $46(30)$ \\
\hline Widower & $6(3.9)$ \\
\hline Divorced & $24(15.6)$ \\
\hline Separated & $12(8)$ \\
\hline \multicolumn{2}{|l|}{ Occupation } \\
\hline Employed & $29(18.9)$ \\
\hline Student & $28(18.3)$ \\
\hline Unemployed & $68(44.5)$ \\
\hline Other & $28(18.3)$ \\
\hline \multicolumn{2}{|l|}{ Age of injury } \\
\hline $18-30$ & $84(54.9)$ \\
\hline $31-43$ & $40(26.1)$ \\
\hline $44-65$ & $29(19)$ \\
\hline \multicolumn{2}{|l|}{ Cause of injury } \\
\hline Motor vehicle crashes & $76(49.7)$ \\
\hline Violence & $24(15.7)$ \\
\hline Fall & $21(13.6)$ \\
\hline Sports & $24(15.7)$ \\
\hline Other causes & $8(5.2)$ \\
\hline \multicolumn{2}{|l|}{ Schooling } \\
\hline Illiterate & $21(13.7)$ \\
\hline Basic education & $37(24.2)$ \\
\hline Moderate education & $57(37.3)$ \\
\hline Higher education & $38(24.8)$ \\
\hline \multicolumn{2}{|l|}{ Level of injury } \\
\hline Cervical & $72(47)$ \\
\hline Thoracic & $43(28.1)$ \\
\hline Lumbosacral & $38(24.9)$ \\
\hline
\end{tabular}


Yazdanshenas Ghazwin Met al.

Table 2. Domain Scores in Individuals With Spinal Cord Injury And General Population

\begin{tabular}{lccc}
\hline Domains & $\begin{array}{c}\text { General Population for Males } \\
(\mathbf{N}=\mathbf{1 9 9 7})^{\mathrm{a}}\end{array}$ & $\begin{array}{c}\text { Spinal Cord Injury for Males } \\
(\mathbf{N}=\mathbf{1 5 3})^{\mathrm{a}}\end{array}$ & P Value \\
\hline Physical functioning & $87.8 \pm 19.0$ & $28.2 \pm 25.3$ & $<0.0001$ \\
Physical role functioning & $73.8 \pm 36.4$ & $54.6 \pm 35.6$ & $<0.0001$ \\
Emotional role functioning & $70.1 \pm 39.7$ & $59.7 \pm 41.2$ & 0.002 \\
Vitality & $68.9 \pm 16.2$ & $61.0 \pm 19.5$ & $<0.0001$ \\
Mental health & $69.2 \pm 17.1$ & $70.5 \pm 19.6$ & 0.370 \\
Social functioning & $78.0 \pm 23.5$ & $63.1 \pm 22.8$ & $<0.0001$ \\
Bodily pain & $82.7 \pm 23.4$ & $69.8 \pm 26.4$ & $<0.0001$ \\
General health & $70.2 \pm 19.6$ & $50.0 \pm 9.8$ & $<0.0001$ \\
\hline a Data is presented as Mean \pm SD. & & &
\end{tabular}

\section{Results}

Total of 153 males with SCI with mean age of $33.10 \pm 8.08$ years participated in this study. Marital status was single in $65(42.5 \%)$ of patients and married in $46(30 \%)$. Six men (3.9\%) were widower, 24 men were divorced (15.6\%) and 12 patients (8\%) were separated (without official divorce). Table 1 illustrates the baseline characteristics of these patients. The most common cause of injury was road accidents (49.7\%) and cervical level injury was the most common (47\%). The majority of patients were unemployed. Age at the time of injury occurrence was mostly between 18 and 30 years old (54.9\%). Fifty-eight patients (37.9\%) were illiterate or had only primary educational level.

Mean score in domain of physical functioning was 28.2 \pm 25.3 in men with SCI, which was significantly lower than the general population $(87.8 \pm 19.0)(\mathrm{P}<0.0001)$. Mean scores in physical role functioning were $73.8 \pm 36.4$ and $54.6 \pm 35.6$ in general population and patients with SCI, respectively ( $\mathrm{P}<0.0001)$. Similarly, scores in emotional role functioning was significantly higher in general population (P: 0.002). Table 2 shows the mean scores in each domain in general population and Iranian men with SCI. There was no significant difference between patients with SCI and general population in domain of mental health (mean scores of $69.2 \pm 17.1$ and $70.5 \pm 19.6$ in general and SCI population, respectively) $(\mathrm{P}=0.37)$. Scores in general population were significantly higher in domains of vitality, social functioning, bodily pain and general health $(\mathrm{P}<0.0001)$.

\section{Discussion}

In the present study, the QoL of Iranian men with SCI was compared with general population. Our results show that patients with SCI have significantly reduced QoL in all domains except in domain of mental health.

Our study has shown that about two-thirds of our samples did not acquire employment following their injury, which is in line with Tasiemski et al. (18) investigation. In the present study, we found that about one-sixth of Iranian men with SCI (15.6\%) were divorced and two-third of these divorces occurred after SCI, which estimates the approximate divorce rate of $11 \%$ after SCI among Iranian males. Previously, it has been reported that divorce rate after SCI is 1.5-2.5 times higher than that of the general population $(19,20)$, which occurs mostly in the first three years after SCI (21). However, since news stations report a divorce rate of $15 \%$ in general population in Iran (1 in each 6.5 marriages) (22), it seems that there is no significant difference between the divorce rate of Iranian general population and men after SCI.

Similar to results in Devivo et al. investigation (23), we found that road accidents were the most common cause s of SCI. However, they reported higher rate of injuries caused by falling than violence, while our study revealed violence as the second common cause of spinal cord injury following traffic accidents.

The SF-36 has been validated and reported to be a reliable tool for assessment of QoL in the general population (24-26) as well as in different patients groups (27, 28). Previously, Westgren and Levi reported that scores of QoL (obtained by SF-36 questionnaire) are significantly lower in all domains compared with able-bodied individuals (28), which is in consistency with our results. Similar finding has also been reported in previous literatures (2937). However, here we detected that in domain of mental health, scores in Iranian men with SCI are similar to those of general population. This result is in conformity with Kreuter et al. and Middleton et al. reports, since they have shown absence of significant differences between persons with SCI and normal population in mental health domain $(38,39)$. Possible explanation for this similarity can be due to development of mental maturity as a consequence of coping with chronic stressful conditions. It is expected that patients with disability report reduced QoL in the domains of physical functioning; but scores in domain of mental health are reduced after SCI, which is due to healthy mental condition and probably higher mental maturity in affected patients.

While our study has illustrated lower scores of QoL in men with SCI compared with normal subjects in seven 
domains of SF-36 questionnaire, there are many investigations that support the reduced scores in all eight domains (37-42). One reason for this controversy can be due to existence of differences between genders. All these investigations had considered both males and females; however, here we only investigated men with SCI. Mousavi et al.(43) showed that females with SCI had reduced scores in all domains of SF-36 except for domain of vitality in comparison with general population. By considering the results from his study, existence of a sexual polymorphism in the pattern of QoL scores after SCI can be suggested.

Our study shows that Iranian men with SCI have significantly reduced health-related QoL assessed by Short Form of SF-36 questionnaire in all studied domains except for domain of mental health. It is expected to observe reduced scores in physical functioning in patients with disability. However, similar scores in domain of mental health between men with SCI and able-bodied subjects shows existence of intact mental health or even some levels of mental maturation due to coping with hard and stressful conditions.

This study gives statistics on the QoL in Iranian men with SCI. Since it is essential to have background statistics on both genders, it is recommended that further studies consider both sexes to describe the present condition of these patients with adequate statistics.

\section{Acknowledgements}

Special thanks goes to individuals with SCI who entered the study. We would like to thank Dr. Montazeri and his coworkers for their nice manuscript about the SF-36, translation and validation study of the Iranian version. This study was designed and performed in the Brain and Spinal Injury Research Center (BASIR) and we would like to thank all the staff who helped us in the progress of this investigation.

\section{Authors' Contributions}

Manijeh Yazdanshenas Ghazwin contributed to study design and data collection. Amir Hossein Tavakoli contributed to study design, patients' recruitment and data collection and obtained the ethical approve. Dr. Samira Chaibakhsh contributed to statistical analysis and study design. Dr. Sahar Latifi contributed to writing the manuscript. Davood Koushki contributed to writing and editing the manuscript.

\section{Financial Disclosure}

This study was financially supported by Tehran University of Medical Sciences. To our knowledge, no conflict of interest exists in any terms and conditions related to this paper.

\section{Funding/Support}

This study was financially supported by Tehran University of Medical Sciences.

\section{References}

1. Gerhart KA, Koziol-McLain J, Lowenstein SR, Whiteneck GG. Quality of life following spinal cord injury: knowledge and attitudes of emergency care providers. Ann Emerg Med.1994;23(4):807-12.

2. Guttmann L. Spinal cord injuries: comprehensive management and research.London: Blackwell Scientific; 1973.

3. Wyndaele M, Wyndaele JJ. Incidence, prevalence and epidemiology of spinal cord injury: what learns a worldwide literature survey? Spinal Cord. 2006;44(9):523-9.

4. Wan GJ, Counte MA, Cella DF. A framework for organizing healthrelated quality of life research. In: Dobrzykowski EA editor. Essential Readings in Rehabilitation Outcomes Measurement: Application, Methodology, and Technology.. Gaithersburg, Maryland: Aspen; 1998. pp. 16-21.

5. Schumaker S, Anderson R, Czajikowski S. Psychological tests and scales. In: Spilker B editor. Quality of life assessments in clinical trials.. New York: Raven Press;1990. pp. 95-113.

6. Smith BM, LaVela SL, Weaver FM. Health-related quality of life for veterans with spinal cord injury. Spinal Cord. 2008;46(7):507-12.

7. Dijkers M. Quality of life after spinal cord injury: a meta analysis of the effects of disablement components. Spinal Cord. 1997;35(12):829-40.

8. Post MW, Van Dijk AJ, Van Asbeck FW, Schrijvers AJ. Life satisfaction of persons with spinal cord injury compared to a population group. Scand J Rehabil Med.1998;30(1):23-30.

9. Budh CN, Osteraker AL. Life satisfaction in individuals with a spinal cord injury and pain. Clin Rehabil. 2007;21(1):89-96.

10. Kennedy P, Rogers BA. Anxiety and depression after spinal cord injury: a longitudinal analysis. Arch Phys Med Rehabil. 2000;81(7):932-7.

11. Kemp B, Krause JS, Adkins R. Depression among African Americans, Latinos, and Caucasians with spinal cord injury: A exploratory study. Rehabil Psychol.1999;44(3):235-247.

12. Tate DG, Forchheimer MB, Krause JS, Meade MA, Bombardier CH. Patterns of alcohol and substance use and abuse in persons with spinal cord injury: risk factors and correlates. Arch Phys Med Rehabil. 2004;85(11):1837-47

13. Priebe MM, Chiodo AE, Scelza WM, Kirshblum SC, Wuermser LA Ho CH. Spinal cord injury medicine. 6. Economic and societal issues in spinal cord injury. Arch Phys Med Rehabil. 2007;88(3 Suppl 1):S84-8.

14. Elliott TR, Rivera P. Spinal cord injury. In: Nezu A, Nezu C, Geller P editors. Handbook of Psychology, Health Psychology.. New Jersey: Wiley; 2003. pp. 415-35.

15. Fisher TL, Laud PW, Byfield MG, Brown TT, Hayat MJ, Fiedler IG Sexual health after spinal cord injury: a longitudinal study. Arch Phys Med Rehabil. 2002;83(8):1043-51.

16. Montazeri A, Goshtasebi A, Vahdaninia M, Gandek B. The Short Form Health Survey (SF-36): translation and validation study of the Iranian version. Qual Life Res. 2005;14(3):875-82.

17. Ware JE, Snow KK, Kosinski M, Gandek B. SF-36 health survey: manual and interpretation guide.Boston: The Health Institute, New England Medical Center;1993.

18. Tasiemski T, Bergstrom E, Savic G, Gardner BP. Sports, recreation and employment following spinal cord injury-a pilot study. Spinal Cord. 2000;38(3):173-84

19. DeVivo MJ, Hawkins LN, Richards JS, Go BK. Outcomes of post-spinal cord injury marriages. Arch Phys Med Rehabil.1995;76(2):130-8.

20. Dawodu ST. Spinal cord injury: definition, epidemiology, pathophysiology. Emed J. 2001;2(8).

21. Kreuter M. Spinal cord injury and partner relationships. Spinal Cord. 2000;38(1):2-6.

22. http://en.trend.az/iran/2147065.html . Divorce rate reaches alarming level in Iran. 2013.

23. DeVivo MJ, Kartus PL, Rutt RD, Stover SL, Fine PR. The influence of age at time of spinal cord injury on rehabilitation outcome. Arch Neurol. 1990;47(6):687-91.

24. Levi R, Hultling C, Nash MS, Seiger A. The Stockholm spinal cord injury study: 1 . Medical problems in a regional SCI population. Paraplegia. 1995;33(6):308-15.

25. Jenkinson C, Coulter A, Wright L. Short form 36 (SF36) health 


\section{Yazdanshenas Ghazwin Met al.}

survey questionnaire: normative data for adults of working age. $B M J .1993 ; 306(6890): 1437-40$.

26. McHorney CA, Ware JE, Jr., Raczek AE. The MOS 36-Item ShortForm Health Survey (SF-36): II. Psychometric and clinical tests of validity in measuring physical and mental health constructs. Med Care. 1993;31(3):247-63.

27. Sullivan M, Karlsson J, Ware JE, Jr.. The Swedish SF-36 Health Survey-I. Evaluation of data quality, scaling assumptions, reliability and construct validity across general populations in Sweden. Soc Sci Med.1995;41(10):1349-58.

28. Westgren N, Levi R. Quality of life and traumatic spinal cord injury. Arch Phys Med Rehabil. 1998;79(11):1433-9.

29. Clayton KS, Chubon RA. Factors associated with the quality of life of long-term spinal cord injured persons. Arch Phys Med Rehabil. 1994;75(6):633-8.

30. Fuhrer MJ, Rintala DH, Hart KA, Clearman R, Young ME. Relationship of life satisfaction to impairment, disability, and handicap among persons with spinal cord injury living in the community. Arch Phys Med Rehabil. 1992;73(6):552-7.

31. Leduc BE, Lepage Y. Health-related quality of life after spinal cord injury. Disabil Rehabil. 2002;24(4):196-202.

32. Lucke KT, Coccia H, Goode JS, Lucke JF. Quality of life in spinal cord injured individuals and their caregivers during the initial 6 months following rehabilitation. Qual Life Res. 2004;13(1):97-110.

33. Unalan H, Celik B, Sahin A, Caglar N, Esen S, Karamehmetoglu SS. Quality of Life After Spinal Cord Injury: The Comparison of the SF-36 Health Survey and Its Spinal Cord Injury-modified Version in Assessing the Health Status of People With Spinal Cord Injury. Neurosurgery Quarterly. 2007;17(3):175-9.

34. Lidal IB, Veenstra M, Hjeltnes N, Biering-Sorensen F. Health-relat- ed quality of life in persons with long-standing spinal cord injury. Spinal Cord. 2008;46(11):710-5.

35. Arango-Lasprilla JC, Nicholls E, Olivera SL, Perdomo JL, Arango JA. Health-related quality of life in individuals with spinal cord injury in Colombia, South America. NeuroRehabilitation. 2010;27(4):313-9.

36. Celik B, Gultekin O, Beydogan A, Caglar N. Domain-specific quality of life assesment in spinal cord injured patients. Int J Rehabil Res. 2007;30(2):97-101.

37. Oh SJ, Ku JH, Jeon HG, Shin HI, Paik NJ, Yoo T. Health-related quality of life of patients using clean intermittent catheterization for neurogenic bladder secondary to spinal cord injury. Urology. 2005;65(2):306-10.

38. Kreuter M, Siosteen A, Erkholm B, Bystrom U, Brown DJ. Health and quality of life of persons with spinal cord lesion in Australia and Sweden. Spinal Cord. 2005;43(2):123-9.

39. Middleton J, Tran Y, Craig A. Relationship between quality of life and self-efficacy in persons with spinal cord injuries. Arch Phys Med Rehabil. 2007;88(12):1643-8.

40. Elfstrom M, Ryden A, Kreuter M, Taft C, Sullivan M. Relations between coping strategies and health-related quality of life in patients with spinal cord lesion.J Rehabil Med. 2005;37(1):9-16.

41. Forchheimer M, McAweeney M, Tate DG. Use of the SF-36 among persons with spinal cord injury. Am J Phys Med Rehabil. 2004;83(5):390-5.

42. Andresen EM, Fouts BS, Romeis JC, Brownson CA. Performance of health-related quality-of-life instruments in a spinal cord injured population. Arch Phys Med Rehabil. 1999;80(8):877-84.

43. Mousavi B, Montazeri A, Soroush MR. [Quality of life in spinal cord injured female veterans]. Payesh. 2008;7(1):75-81. 